\title{
DESPOLITIZAÇÃO, DESMOTIVAÇÃO, LEGITIMIDADE
}

\author{
André Berten \\ Professor Emérito da Universidade de Louvain \\ andre.berten@gmail.com
}

\section{Resumo}

As teorias políticas de inspiração kantiana propõem teorias da justiça, do direito e da democracia que pretendem poder ser justificadas racionalmente, seja a partir de uma teoria do contrato social, ou do consenso das pessoas razoáveis, ou de uma deliberação argumentada. Uma das pressuposições dessas teorias é que as pessoas podem ser motivadas pelo que aparece como mais justo, melhor, mais respeitoso das pessoas. Porém, o que podemos chamar de “amor da justiça” ou mais simplesmente um “desejo de justiça” implica sentimentos ou até paixões. Do outro lado, sabemos muito bem como as paixões políticas podem ser avassaladoras, como nos casos extremos do nazismo ou dos fascismos. É por isso que talvez deveríamos avaliar melhor o papel dos sentimentos e do afetivo no jogo político.

Palavras-chave: Teoria política. Paixões políticas. Teoria da justiça.

\section{DESPOLITIZATION, DEMOTIVATION, LEGITIMACY}

\begin{abstract}
Political theories of Kantian inspiration propose theories of justice, law, and democracy that claim to be rationally justified, either from a theory of the social contract, or from the consensus of reasonable people, or from reasoned deliberation. One of the assumptions of these theories is that people can be motivated by what appears to be fairer, better, more respectful of people. However, what we may call "love of justice" or more simply a "desire for justice" implies feelings or even passions. On the other hand, we know very well how political passions can be overwhelming, as in extreme cases of Nazism or fascism. That is why perhaps we should better assess the role of feelings and affective in the political game.
\end{abstract}

Key-words: Political theory. Political passions. Theory of justice. 


\section{0 fenômeno da despolitização}

Um síntoma negativo dessa importância dos sentimentos na motivação política é precisamente a despolitização, isto é a desmotivação política. O desinteresse pela política, pela esfera pública em geral, é um fenômeno variável, mas que na crise contemporânea das democracias - social-democracias e democracias liberais - se tornou realmente preocupante. Me parece que há dois tipos de explicação desse fenômeno: uma explicação pela ausência de motivos racionais de acreditar na capacidade da política de realizar um mínimo de justiça social; e uma explicação pela ausência de confiança no pessoal político, sua honestidade, sua capacidade de suscitar um investimento emotivo. Nos dois casos, o poder político perde sua legitimidade ou, mais precisamente a crença na sua legitimidade desaparece.

A despolitização é um fenômeno empírico evidente. Por exemplo:

Sondagem nacional do Núcleo de Pesquisa em Políticas Públicas da USP, realizada em março [de 2014], constatou que $76 \%$ dos ouvidos não confiavam no Congresso, 73\% não acreditavam no empresariado e 70\% não creem no respeito às leis no Brasil. Junte-se a esses dados a pesquisa Datafolha de maio em que seis em cada dez brasileiros prefeririam não votar nas próximas eleições, e podemos afirmar: a credibilidade das instituições despenca (ALENCAR, 2014).

Em 2016, nas eleições presidenciais americanas, a taxa de participação ao voto foi somente de 54,2\%. É a taxa mais baixa já notada. Em 2016 igualmente, nas eleições municipais no Brasil, os votos brancos, nulos e as abstenções chegaram a 32,5\% (em 2012, 26,5\%). O Tribunal Superior Eleitoral constatou que cerca de 7,1 milhões de eleitores não compareceram às urnas no $2^{\circ}$ turno.

Há sempre também elementos contextuais particulares. Sem dúvida, o espetáculo de uma câmara de deputados votando em abril de 2016 o impeachment de uma presidente eleita confirmou e aprofundou essa desconfiança dos cidadãos a respeito da política. Do ponto de vista racional, podemos dizer que, nessa sessão, não houve nenhum signo de republicanismo e de democracia: faltaram três características constitutivas, três características que, penso eu, devem ser ao fundamento de uma concepção moderna e justa do republicanismo e da democracia. O primeiro elemento é a separação do público e do privado: as opções políticas não se determinam em função da família, dos filhos, da mulher mas em função do bem comum, do interesse geral. O apelo à honra de pessoas particulares e próximas é a base do nepotismo e, 
de maneira mais larga, do clientelismo. O segundo elemento constitutivo é a separação da religião e da política, da Igreja (das igrejas) e do Estado. O Estado secular, neutro a respeito de todas as crenças, de todas as concepções do bem e das formas de vida, é a condição mesmo de um Estado democrático numa sociedade pluralista, isto é, no tipo de sociedade que quase necessariamente se desenvolve quando há a liberdade de pensamento e de expressão. E enfim, terceiro elemento - o mais difícil de alcançar, mesmo nas democracias maduras - é o fato que os representantes eleitos não são representantes de um partido, de uma cidade, de um estado, de interesses particulares, mas representantes do povo - o que é a única maneira de pensar a deliberação pública e a formação de uma concepção política justa. Esses três elementos opõem uma certa forma de universalismo aos particularismos de todo tipo. Porém, devemos reconhecer que os particularismos são o lugar dos sentimentos, dos apegos, do afetivo e mesmo das paixões. Em um certo sentido, esse voto é também significativo do que podemos chamar de maneira geral de motivação política. As motivações particulares, familiares, privadas, religiosas, provincianas ou ufanistas, muitas vezes são as motivações reais que, sob o manto do bem comum ou dos direitos humanos ou do crescimento econômico, motivam realmente os cidadãos e particularmente os políticos. Séria ilusório de exclui-las totalmente. No entanto não podemos aceitar que a política seja inteiramente conduzida pelos sentimentos ou as paixões. Portanto, o problema político — um dos problemas políticos mais difíceis — é o tipo e equilíbrio desejável entre o racional e o passional.

O que se mostrou em 2016 no Brasil é a caricatura de alguns dos males que, através do mundo, afeitam os regimes políticos atuais: o abandono de projetos políticos globais justos e moralmente aceitáveis. É difícil hoje falar de política, no sentido nobre do termo, e principalmente falar de ideais políticos. Talvez o espetáculo político, o palco onde aparecem aqueles que deveriam preocupar-se do bem comum da sociedade, é tão desesperador que desencoraja toda tentativa de defender qualquer política, sabendo que atrás dos discursos edificantes se escondem lutas de poder, ânsia de dinheiro, amoralismo e corrupção.

O apolitismo de uma grande parte da população no mundo contemporâneo não pode deixar de colocar problemas aos que acreditam no valor da democracia. Por que as pessoas, os cidadãos, se desinteressam daquilo que determina uma parte de sua vida, de suas possibilidades de escolha? Aqui se coloca o que poderíamos chamar da questão da motivação política - os motivos pelos quais nos interessaríamos à política, à coisa pública, à “república” - e de maneira mais ampla ainda, a questão da motivação moral - os motivos pelos quais interessariamo-nos 
aos outros em geral. A motivação moral e a motivação política têm chance de emergir - ou têm mais chance de emergir - se um regime político for suscetível de suscitar um consenso ou uma vontade de engajamento. Pensamos, sem poder aqui argumentar, que a única forma de conseguir um consenso real e a longo prazo, é constituir progressivamente uma sociedade com instituiç̧ões mais justas (RAWLS, 1971).

Nossa reflexão sobre o apolitismo não leva a uma generalização sociológica atemporal. Não devemos afastar a possibilidade de engajamento político, ou mesmo de entusiasmo pela coisa pública. Há momentos onde há um movimento popular, como nas manifestações de junho 2013 no Brasil, ou os movimentos que se chamaram de primavera árabe, no Egito ou na Tunísia; ou, há mais tempo já, os movimentos que no leste europeu acabaram com os regimes ditatoriais: nesses casos, aparentemente, há uma participação massiva e o surgimento de reinvindicações que expressam os problemas reais que afetam a população. Mas esses momentos são passageiros ou mesmo efêmeros. E as manifestações são sem pautas definidas e sem liderança. Elas valem como sintomas e pedem uma encarnação institucional - que muitas vezes não vem. Nossa questão não é - não é somente - como canalizar essas reivindicações, mas como traduzir em instituições o conteúdo desse pedido de justiça, ou mais exatamente, como encontrar um equivalente institucional ao que se expressa informalmente.

É verdade que, na história moderna, houve outras formas de politização. Por exemplo, nos momentos onde a "luta de classe" conseguiu a organizar-se: os movimentos operários, as oposições entre socialistas e conservadores. Um dos resultados dessas lutas foi sem dúvida um aprimoramento da democracia e das instituições do Estado de direito. Mas é possível que esses exemplos não sejam de muita ajuda hoje, não somente porque a classe operária se desmoronou na maioria dos países desenvolvidos, mas sobretudo porque a forma contemporânea do capitalismo financeiro mudou profundamente as condições de resistência e de possível mudança. Charles Taylor escreveu que:

o desafio para a democracia liberal é continuar sendo uma democracia liberal particularmente a respeito da participação - quando ela passou além da fase de luta contra os vários tipos de estruturas que beneficiam às elites. A maioria das democracias ocidentais estão nesse estágio, e o nível de participação está caindo. (TAYLOR, 2014).

É importante analisar as principais circunstâncias contemporâneas que provocaram a desmotivação e a despolitização para poder avaliar a significação dos movimentos de protesto 
que surgem de várias formas hoje e que se manifestam por exemplo nos debates a respeito da estatura política de Trump, a respeito da significação do Brexit, a respeito da legitimidade do impeachment, a respeito das consequências sobre a previdência e as condições do trabalho da dominação exacerbada do mercado financeiro. A análise dessas condições permitiria construir um contra-modelo de sociedade e, se há uma recusa das circunstâncias de deshumanização implicada na extensão de um capitalismo financeiro selvagem, podemos supor que existirá um investimento afetivo, manifestando um desejo de justiça.

\section{Algumas razões da despolitização contemporânea}

Uma das razões da não-participação política é o fato que, nas democracias contemporâneas, os projetos políticos entre os partidos de esquerda e de direita se tornaram globalmente indistintos. Nas democracias ditas representativas, mas onde a representação se faz essencialmente através da estrutura partidária, as oposições quase desaparecem: esquerda e direita, social-democratas, conservadores e liberais, parecem todos submetidos aos ditames dos mercados internacionais, dos jogos financeiros. Isto é ligado também ao fato do desaparecimento de classes claramente distintas. Quando a classe operária - e em geral a classe mais pobre - tem acesso a um certo conforto (por exemplo, acesso à propriedade), seus interesses se diversificam. Essa fragmentação torna difícil uma ação político unitária. Às vezes, o compromisso é o resultado de uma negociação entre interesses divergentes. Mas na maioria dos casos, as ditas "classes populares" não têm voz nem expressão e os interesses das faixas mais ricas são pura e simplesmente impostos.

Um outro motivo de despolitização é a forma atual dos meios de comunicação e de informação: numa sociedade de consumo, a comunicação se tornou principalmente um meio de entretenimento. Como, além disso, a mídia depende fundamentalmente do sistema capitalista, o pouco de informação transmitido não permite o que deveria ser um debate numa esfera pública democrática. $\mathrm{O}$ apolitismo se torna então a consequência do conformismo midiático. O consumo se torna o único interesse.

Atrás dessa indiferença política e aproveitando dela, os mecanismos do capitalismo continuam concentrando a riqueza e o poder de uma minoria. Há um fenômeno realmente preocupante quando avaliamos as chances da democracia puder não somente se fortalecer ou até ficar mais participativa, mas somente continuar existindo quando se constata o aumento massivo das desigualdades socio-econômicas desde as últimas décadas do século XX até hoje. 
(PIKETTY, 2013). Podemos fazer a hipótese de que há uma interdependência importante entre a desigualdade econômica e social de um lado, e do outro lado as motivações dos cidadãos ou das pessoas em geral. É provável que uma sociedade profundamente injusta suscite somente movimentos de revolta pontuais, e na medida em que esses movimentos não desembocam sobre mudanças ou resultados, a consequência é um desinteresse ou uma apatia política, resultando do sentimento de impotência. Não é por nada que a Teoria da Justiça de John Rawls defendia, entre os princípios de justiça, um princípio de repartição implicando uma atenção especial para os mais desfavorecidos. Nesse sentido, o livro de Thomas Piketty (2013) sobre o capitalismo do século XXI e sobre as desigualdades crescentes oferece um quadro que pode explicar uma boa parte da despolitização. De maneira assustadora, Piketty, analisando séries de dados sobre 250 anos, mostra que a concentração sempre crescente da riqueza não é auto-corretiva - que as contradições do capitalismo não implicam seu fim. A redistribuição das rendas vai para os detentores do capital e não para os assalariados. Pelo contrário, o movimento de concentração cria o que ele chama de um capitalismo patrimonial no qual um número reduzido de famílias controlem a maior parte da riqueza ${ }^{1}$. Essa situação só poderia ser corrigida por uma intervenção do Estado - sem a qual a ordem democrática se tornará cada vez mais ameaçada. Podemos também tirar uma conclusão dessas teses: o desmoronamento da democracia é equivalente a uma desmotivação desde que não existem mais canais institucionais suscetíveis de opor-se a essa dinâmica.

Enfim, e provavelmente a causa mais profunda dessa desmotivação é o fenômeno de globalização ou mundialização ${ }^{2}$. Não devemos pensar essa deriva somente como uma autonomização dos mercados financeiros correlativa de uma impotência dos Estados em imporem políticas independentes. Aparentemente, segundo a vulgate, o movimento neo-liberal implica que o Estado deixou de exercer sua autoridade e sua capacidade de regular a economia, abandonando aos mercados a totalidade do espaço. Esse afastamento do Estado é também o resultado da globalização que torna as políticas nacionais impotentes. Porém, esse lugar comum esconde o fato que na realidade o Estado age positivamente para sustentar e reinforçar os mercados. A tese de Suzanne Mettler (2011), por exemplo, é que a realidade não é somente uma ausência do Estado, mas o fato que o Estado assiste e produz essa vacância de poder -

\footnotetext{
${ }^{1}$ Uma outra tese de Pyketti é importante: esse movimento de concetração das riquezas trava o desenvolvimento. ${ }^{2}$ A globalização é objeto de muitos debates. Encontra-se um excelente conjunto de estudos sobre esse assunto em HELD David \& McGREW Anthony (Eds.) (2003).
} 
lembrando as velhas teses marxistas do Estado ao serviço da classe dominante. O título do livro de Mettler indica uma da maneira de isso ocorrer: The Submerged State. As políticas governamentais são implementadas por entidades e organizações privadas. Por exemplo, o “Obamacare” implica compromissos enormes com as companhias de seguro, a indústria farmacêutica e o complexo hospitalar. Mettler mostra que isso contradiz a natureza mesma da democracia na medida em que o funcionamento real da ação do Estado fica escondida. Uma pesquisa citada mostra que, como consequência desse engajamento escondido do Estado, os cidadãos informados mudam a sua consciência política e internalizam uma representação totalmente distorcida do funcionamento real da máquina política (Hacker and Pierson, 2010).

Indiquei esquematicamente alguns dos elementos da situação atual que permitem entender a despolitização e desmotivação política. Sugeri também que um dos problemas políticos centrais é o equilíbrio delicado entre a razão e a paixão nas motivações políticas e a necessidade de propor projetos políticos suscetíveis de suscitar um “desejo de justiça”, isto é um sentimento positivo a respeito do que é proposto. No entanto essa forma de investimento sentimental é sempre perigosa. Pois, há formas de motivação e participação política que não parecem desejáveis. Por exemplo, a politização que se manifesta nos partidos de extremadireita, as reações contra a imigração, contra os estrangeiros. Nos Estados Unidos, o tea-party. E em geral, muitas reações ligadas a um nacionalismo exacerbado. Essas manifestações podem fazer descarrilhar a democracia. Não obstante, essa forma de politização revela uma coisa importante: devemos refletir sobre os motivos destas mobilizações. Claro que há motivações conjunturais - como por exemplo o aumento da imigração ou as consequências da globalização sobre as condições de trabalho, de consumo, de residência etc. Mas essas causas ocasionais levam a una reflexão mais geral sobre o que pode motivar as pessoas: quais são os motivos psicológicos em geral que fazem que uma pessoa queira agir de tal ou tal maneira.

\section{0 problema da motivação política}

A despolitização remete à falta de motivação e vimos quais podem ser as explicações dessa desmotivação. No entanto, a questão da motivação é uma questão complexa. Não posso entrar aqui nos debates sobre a natureza da motivação em geral. Poderíamos partir do esquema simplificado da folk psychology, tentando explicar o comportamento ou a ação em termos de crenças e desejos. É uma explicação de tipo “teleólogica” na qual o objeto desejado, a 
finalidade, o alvo, tem a prioridade: agimos de uma certa maneira porque queremos satisfazer tal ou tal desejo. As crenças dizem a respeito dos objetos suscetíveis de realizar essa finalidade, do contexto que torna a realização desse desejo possível, impossível, provável. Embora esse esquema pudesse dar conta da lógica da maioria das ações, ele não diz nada ou quase nada sobre a formação das crenças, sobre sua força, sobre o fato que às vezes ou muitas vezes há crenças contraditórias. A folk psychology propõe uma explicação “individualista” da ação válida desde que as crenças são dadas, sem questionar sua origem, sua força, sua qualificação moral. Evocaremos essa dificuldade apresentando um aspecto do individualismo metodológico da sociologia de Weber no que diz respeito a questão da legitimidade. Mas notemos logo que as motivações políticas podendo decorrer de paixões - como nos nacionalismos e até nos fascismos - a racionalidade da ação individual se dilua completamente em representações ou crenças coletivas das quais o indivíduo não dispõe explicitamente e, portanto, não pode utilizálas para avaliar a racionalidade de seu próprio agir.

De maneira mais branda, os populismos apoiaram-se também sobre as partes mais instintivas, ou mesmo violentas das motivações. Notemos que, em geral, as motivações vêm de sentimentos ou apegos particulares: minha pessoa, minha família, minha terra, minha província, minha pátria, minha religião, etc. Devemos perguntar-nos em que medida representações abstratas - como a ideia de justiça, ou as representações dos direitos humanos — são suscetíveis de motivar realmente as pessoas, em que medida uma preocupação pela justiça pode ser uma motivação para os cidadãos apoiarem um regime político. E, admitindo que as paixões políticas fazem sempre parte dessas motivações, em que contexto as paixões políticas podem apoiar políticas justas, igualitárias, democráticas em vez de levar a sistemas autoritários, nacionalistas ou excludentes. As paixões políticas, e mais geralmente o interesse para com o coletivo, pressupõem uma motivação, isto é um estado psicológico que leva as pessoas a agir de tal ou tal maneira. Em outras palavras, a motivação pode ser pensada, ou deve ser pensada, como um desejo. A questão da motivação política implica uma teoria do desejo. Seria pretencioso propor uma teoria do desejo em si, mas gostaria de colocar a questão de saber se por exemplo uma expressão como "um desejo de justiça” tem um sentido.

É óbvio que há uma infinidade de objetos do desejo e sabemos que para determinar os objetos do desejo, uma consideração das “necessidades” é totalmente insuficiente. Do ponto de vista político, a cegueira do utilitarismo - pensando que a política pode reduzir-se a uma economia política - é evidente. Não obstante, a despolitização, o desinteresse pelo coletivo, 
pelo bem comum, que marca os comportamentos individualistas das sociedades pós-modernas coloca uma questão sobre um aspecto talvez pouco explorado das mudanças do desejo nas sociedades ditas de consumo. Não basta dizer, por exemplo, que uma parte, a maior parte, dos nossos desejos são determinados pelas imagens publicitárias. O desenvolvimento econômico enquanto tal - não somente capitalista - implica mais que uma modificação dos objetos do desejo, implica uma mudança mais profunda.

Nas sociedades tradicionais, as pessoas não pensavam que sua vida seria diferente da vida de seus pais. Havia não somente uma limitação forte dos objetos possíveis do desejo, mas havia também uma aceitação generalizada dos estados de coisa existentes e a consciência da impossibilidade de mudar o contexto do mundo da vida. Nesse caso, o que poderia aparecer como uma ausência de motivação política significava simplesmente que não existia lugar para a ação política, pelo menos para a maioria das pessoas. Poe exemplo, a descrição do político, do espaço público, por Hannah Arendt (1958) é a descrição de uma esfera de discussão, limitada no espaço e no tempo, para uma minoria de cidadãos, isto é uma minoria de agentes políticos. É por isso que podemos aceitar as teses de Bernard Williams (1995) mostrando que, ao contrário das esperanças dos tradicionalistas, não é possível nem desejável voltar ao modelo da república antiga. É somente com uma ideia generalizada de democracia que se abra um espaço de ação política para os cidadãos em geral.

No mundo do moderno capitalismo de consumo, surgem tipos completamente diferentes de expectativas. Se não estou mais obrigado de viver segundo os modelos de meus pais, o futuro se torna indeterminado e a diferença entre desejo e necessidades se torna explícita - ou mais precisamente: a indeterminação das necessidades acarreta a ilusão que sua satisfação poderia tapar o furo do desejo. A fronteira entre o supérfluo e a necessidade se borra. O indivíduo toma consciência de seus desejos próprios. A possibilidade do individualismo reside nessa indeterminação das perspectivas de vida, dos objetos do desejo.

Essas transformações das condições gerais da vida na modernidade foi o objeto de inúmeras análises, sociológicas, antropológicas, psicológicas e políticas. Desde Marx, Nietzsche, Heidegger e tantos outros, as críticas da modernidade não faltaram. Uma das consequências dessas mudanças é sem dúvida a dificuldade de segurar o laço social. Habermas, no Discurso filosófico da modernidade, notava: 
Desde o fim do século XVIII, o discurso da modernidade teve um único tema, ainda que sob títulos sempre renovados: o enfraquecimento das forças de coesão social, a privatização e a cisão, em suma: aquelas deformações de uma práxis cotidiana racionalizada de modo unilateral, que provocam a necessidade de um equivalente ao poder de unificação da religião. (HABERMAS, 2002, p. 197) ${ }^{3}$

Admitindo que a religião nas sociedades tradicionais constituía um quadro comum e era fonte das motivações sociais, a procura de um equivalente ao poder de unificação da religião é equivalente a uma procura de uma fonte de motivação que seja suscetível de reorientar os indivíduos para com o interesse público. Numa sociedade onde a ciência e a técnica controlam cada vez mais as contingências da natureza, onde as funções tradicionais da religião e da metafísica perderam sua significação de visão do mundo e sua força normativa, os indivíduos devem encontrar outras fontes de motivação que a religião. É nessa falta de fonte tradicional ou social de motivação que se inscreve o individualismo e as teses da folk psychology. Se a motivação não é dada pela sociedade, pela cultura, ela só pode proceder dos desejos individuais. A representação clássica da ação explicada em termos de crenças e desejos acorda a prioridade ao desejo porque é considerado como a única fonte de motivação. Essa tese foi formulada brutalmente por David Hume quando afirmava que a razão nunca motiva, mas é escrava do desejo. “A razão é, e deve ser, apenas a escrava das paixões, e não pode aspirar a outra função além de servir e obedecer a elas”. (HUME, 2000, p. 451) Nos termos da folk psychology, isso significação que as crenças enquanto tais nunca podem motivar, mas são totalmente dependentes das paixões ou do desejo.

No entanto, essa representação é simples demais e, entre outros, não permite entender em que uma crença, inclusive uma crença racional, pode motivar. Uma questão central que perpassa a Teoria da Justiça de Rawls é de pensar a possibilidade de um desejo de justiça. Um desejo de justiça é imediatamente político. Porém podemos admitir com Paul Ricœur que o desejo de justiça não é um desejo natural. O que é quase natural, ou pelo menos o que espontaneamente pode surgir de maneira episódica, é uma revolta contra as injustiças. É mais fácil ter uma representação de uma injustiça que de elaborar um modelo de sociedade justa. É por isso que as discussões sobre a sociedade ideal são conflitivas, mesmo entre pessoas que

\footnotetext{
${ }^{3}$ Ver também HABERMAS, 2010, p. 18-19.
} 
querem sinceramente defender a justiça. À ideia de justiça devemos acrescentar a ideia de legitimidade e a ideia de justificação. A ideia de legitimidade, porque qualquer modelo político deve parecer legítimo para com os cidadãos. E qualquer modelo de sociedade justa deve poder ser justificada.

Falar de apolitismo ou de despolitização é falar de falta de motivação. Uma das explicações dessa desmotivação repousa no fato de que nenhuma das opções políticas propostas parece merecer o apoio dos cidadãos. Uma maneira de qualificar essa situação e de dizer que o governo em geral falta de legitimidade e falar de falta de legitimidade é falar de falta de motivação. Não obstante, dizer que um regime político que garante na medida do possível a justiça é um regime legítimo é ambíguo não somente porque o conceito de legitimidade é elemesmo um conceito ambíguo — ou empírico, ou normativo —, mas também porque legitimidade e justiça não são conceitos intercambiáveis.

\section{A legitimidade, um fenômeno empírico}

A legitimidade pode primeiro ser considerada do ponto de vista empírico: dizer que uma ordem social é legítima é só dizer que é amplamente aceita entre as pessoas. É observar quando e como e em que medida os sujeitos reconhecem o poder ao qual são submetidos. Empiricamente, podemos analisar o reconhecimento ou a aceitação de um regime político como um fenômeno psicológico ou como um fenômeno sociológico, ou como um fenômeno simultaneamente psicológico e sociológico. É nesse sentido, por exemplo, que Charles Taylor (1985b) fala de “crise de legitimação”, quando as condições de reconhecimento não são mais seguradas.

A questão da legitimidade é difícil quando a despolitização se torna um fenômeno generalizado, quando ninguém ou quase ninguém considera que os políticos são honestos, quando a corrupção se tornou uma maneira normal de adquirir o poder. No entanto, todo e qualquer poder precisa de um mínimo de reconhecimento ou de legitimidade.

Para ilustrar essa perspectiva, nos referimos a Max Weber e a seu individualismo metodológico, isto é, a um ponto de vista onde a compreensão dos motivos pelos quais os indivíduos reconhecem a legitimidade do poder refere de maneira geral aos motivos da crença e da ação: por que os sujeitos acreditam no direito de uma pessoa ou de um grupo ou de uma instituição exercerem um poder sobre eles e acreditam que devem obedecer e, geralmente, 
obedecem às ordens desse poder? A perspectiva do individualismo metodológico é sociológico na medida em que as crenças são em geral crenças sociais que podem ser tipificadas.

Weber articula legitimidade e dominação e considera os dois fenômenos como realidades empíricas. A dominação é “a chance, para ordens específicas, de ser obedecidas por um grupo determinado de indivíduos”. (WEBER, 1971, p. 219). Aqui não se fala de uma justificação, mas simplesmente do fato que certos indivíduos - um grupo qualquer, como pode ser um conjunto de cidadãos - obedecem a uma ordem. As motivações a obedecer podem ser diversas, indo do medo da violência até o reconhecimento da legitimidade do poder.

'Nesse sentido, a dominação (a 'autoridade’) pode repousar, num caso particular, sobre os motivos os mais diversos de docilidade: do morno hábito às mais puras considerações racionais em finalidade”. (WEBER, 1971, p. 219).

No entanto, Weber (1971, p. 219) acrescenta: “Toda verdadeira relação de dominação comporta um mínimo de vontade de obedecer, por conseguinte, um interesse, exterior ou interior, a obedecer”.

Notemos que essa vontade de obedecer não significa o reconhecimento da legitimidade do poder. Posso obedecer a um sistema político que favorece meus interesses econômicos sem me preocupar da justiça, sem me preocupar da questão de saber se o regime é justificável ou não. Da mesma maneira, um poder puramente opressivo, funcionando somente a partir do medo que ele inspira, pode se manter sem reconhecimento de sua legitimidade. Basta um corpo de funcionários dedicados ao poder e exercendo a violência para segurar a dominação.

Não obstante, Weber (1971) pensa que o interesse, exterior ou interior, não é suficiente para sustentar o poder de maneira estável.

A experiência mostra que nenhuma dominação se satisfaz de fundar sua permanência sobre motivos ou estritamente materiais, ou estritamente afetivos, ou estritamente racionais em valor. Pelo contrário, todas as dominações procuram despertar e manter a crença na sua 'legitimidade'. (WEBER, 1971, p. 220).

Essa observação é importante e deve ser bem entendida. Os três tipos de motivos evocados correspondem ao interesse econômico, a crença carismática à legitimidade do poder de uma pessoa excepcional ou à crença tradicional e indiscutível — geralmente religiosa — no caráter sagrado do poder. Essas crenças podem se tornar rotineiras e, nesse caso, a questão da legitimidade quase não se coloca. Weber estima que nenhum desses motivos de submissão é suficiente para manter a estabilidade do poder. No entanto, essa afirmação de Weber me parece 
válida somente no contexto da modernidade. Pois, nas sociedades tradicionais, podemos notar que a dominação "racional em valor" - que é por exemplo, a dominação fundada sobre a crença religiosa — pôde manter-se de maneira estável durante séculos.

Nos tipos de legitimidade que Weber constrói - tradicional, racional em valor, racional em finalidade — há cada vez uma motivação: uma motivação de tipo religioso, sagrado, ou uma motivação material, econômica, ou uma motivação afetiva, emocional ou passional. Mas essa motivação das pessoas não é suficiente para garantir a manutenção do poder — porque os interesses são variáveis, múltiplos, e geralmente individuais. Isso significa que — é uma constatação empírica segundo Weber - uma sociedade capitalista não pode se estabilizar somente deixando as regras do mercado funcionar livremente, ou mais precisamente, deixando os indivíduos utilizar o mercado para seu interesse exclusivo: é preciso daquilo que Marx chamava de 'ideologia', isto é, de argumentação tentando mostrar socialmente a legitimidade do funcionamento capitalista.

Essa observação de Weber me parece muito importante. O requerimento de legitimidade que parece necessário para justificar o poder faz apelo ou deve fazer apelo ao que podemos desde agora chamar um 'sentimento de justiça' ou um sentimento moral. É importante porque a justificação de um regime — “Por que ser republicano?” — deve apelar a sentimentos morais ou sentimentos de justiça. O que Weber sugere é que a 'crença' na legitimidade de um poder é um elemento imprescindível de seu funcionamento. A crença na legitimidade é uma crença na “justiça”, mesmo se o conceito de justiça aqui é usado de maneira frouxa. Claro, se trata aqui de conceitos empíricos e, de uma certa maneira, da motivação entendida como realidade psicológica, e não da motivação entendida como justificação normativa. Não obstante, o que essa descrição revela é que a normatividade é uma realidade que perpassa nossa vida, que, de uma certa maneira, precisamos justificar nossas crenças ou nossas ações (veja KORSGAARD, 1996). É possível que essa exigência de justificação seja explícita somente em circunstâncias específicas, como o que aconteceu de maneira generalizada na modernidade: do ponto de vista de uma lógica do desenvolvimento, a necessidade de justificação se agrega progressivamente a essa exigência básica de legitimidade.

O que Weber descreveu nessa tipologia das formas de dominação são os tipos de motivações que podem levar os indivíduos a reconhecer a legitimidade de um regime político. É uma maneira de categorizar as possíveis motivações políticas e, portanto, entender melhor o que acontece nas sociedades democráticas, nos seus desvios, as possibilidades de ditatura, de 
nacionalismo, de corrupção. Claro, não devemos hipostasiar essa tipologia, mas podemos usála para entender melhor os motivos que levam os indivíduos a aceitar ou não aceitar a forma democrática dos regimes modernos.

No entanto, a descrição ideal-típica fica ao nível das "razões motivantes" ${ }^{4}$ e não diz nada sobre a qualificação dessa adesão, não diz se a adesão é feita por "boas razões” ou "razões normativas” ou ainda "razões justificativas”. A legitimidade é analisada de maneira empírica: depende da atitude dos cidadãos ou daqueles que são submetidos ao poder. É por isso que Weber fala de formas de “dominação”. Aqui, legitimidade, poder, dominação se confundem. E é um fato que a legitimidade da monarquia se baseava sobre a crença que o rei era depositário de um poder sagrado, divino, conforme a "tradição”. Um herói de guerra - como de Gaule ou Eisenhower - suscitou uma adesão entusiasta que pertence à categoria “carismática”, afetiva, emocional. Hoje em dia, apareceu a crença - uma ideia moderna, amplamente difundida - que um regime é legítimo se respeita as regras democráticas, os procedimentos das eleições, a “racionalidade” procedimental. As pressuposições reais que levam as pessoas a obedecer ao rei, a um ditador, a um governo eleito democraticamente, podem ser todas diferentes.

Esse uso empírico do conceito de legitimidade é central na sociologia, na ciência política. Ele aparece por exemplo ao nível internacional. Pettit, referindo-se a Buchanan (2004), escreve:

O regime pode não ser legítimo na maneira em que se relaciona com seus cidadãos, mas ainda pode contar como membro legítimo da comunidade internacional. (...) Um tal Estado pode não ser democrático ou liberal, em nenhum sentido padrão, mas, numa frase usada nesse contexto por John Rawls, ele pode contar como um regime decente que merece pleno respeito e incorporação no plano internacional. (PETTIT, 2012, p. 146).

Aqui o reconhecimento da legitimidade de um regime político dado é também um fato empírico, mas com outros atores que os cidadãos: é o fato que é aceito na comunidade internacional, qualquer que seja a sua reprovação por exemplo pelos defensores dos direitos humanos. É verdade que, nessas situações, o que está em jogo são principalmente relações de poder. Mas é significativo que na retórica dos discursos oficiais, por exemplo na ONU, apesar de tudo, é preciso de um discurso de justificação — por exemplo quando se debateu a legitimidade da intervenção no Iraque.

\footnotetext{
${ }^{4}$ Sobre essa distinção, veja entre outros Dancy 2000 e Scanlon 1998.
} 
Não pretendemos desqualificar esse uso empírico do conceito de legitimidade, pois ele fornece análises muitas vezes pertinente das motivações reais das pessoas que aceitam como justificado — ou mais ou menos justificado ou injustificado — o modo de governar ou as instituições essenciais de um país. É um fato empírico que em geral reconhecemos a legitimidade de um poder sem interrogar-nos sobre as razões desse reconhecimento. — por exemplo um poder dito democrático - , mas os debates políticos significam que pode acontecer um momento onde o reconhecimento da legitimidade falta, ou a prestação de tal ou tal membro do governo parece ilegítima. Podemos estimar que um político totalmente corrupto não tem mais legitimidade e tentar derrubá-lo, exigir o “impeachment” do presidente ou do primeiro ministro. Quando se fala de crise de legitimidade, no sentido empírico, se diz que o Estado ou o poder não tem mais o apoio da população - como pode aparecer por exemplo numa pesquisa de opinião.

Mas essa perspectiva empírica e descritiva é insuficiente, não porque queremos adotar um ponto de vista moral, mas porque, ficando a um nível estritamente descritivo, poder-se-ia considerar que a submissão a uma ditatura é um fenômeno como um outro e que as críticas eventuais a esses comportamentos de submissão, ou mesmo de aprovação, indicam somente desacordos, diferenças de opiniões, formas opostas de aprovação/desaprovação. Não devemos esquecer que o nazismo na Alemanha, ou o stalinismo na União Soviética, apesar de usar meios violentíssimos para impor seu poder, encontraram no entanto uma aprovação senão de uma maioria dos cidadãos, pelo menos de um muito grande número de pessoas. Se consideramos que as ditaturas não podem receber nossa aprovação, devemos avançar argumentos.

Um indício que pode nos levar a pensar que a questão da legitimidade não é uma questão meramente empírica, mas também não é somente uma questão moral ou idealista, é o fato que é uma questão antiga, que atravessa toda história e está no centro de muitas "filosofias políticas”. Ela foi muitas vezes, desde Aristóteles, considerada a partir de quem tem o poder: um, vários, todos. Monarquia, aristocracia e democracia aparecem como três modelos normativos e, paralelamente, a tirania ou o despotismo, a oligarquia, a oclocracia ou demagogia (veja a Teoria das formas de governo em Bobbio 1980) são as formas pervertidas ou ilegítimas de regime político. Não quero discutir aqui da melhor forma de regime político, mas somente lembrar que a questão do “melhor” regime político é uma questão normativa e não fica ao nível somente descritivo ou empírico. 
O que pode nos perturbar ou acarretar confusões é o fato que a “democracia” hoje em dia parece o regime normativo dominante. Mas isso é totalmente insuficiente para sustentar argumentos a favor dela. Existem hoje em dia monarquias (em geral monarquias constitucionais) e várias formas de despotismo. O contexto em que o modelo democrático se tornou o modelo normativo geralmente valorizado é o contexto da dominação de uma instituição — a ONU — que considera que somente os regimes democráticos podem ser reconhecidos como “decentes”, para usar aqui a expressão de John Rawls na sua tentativa de aplicar a teoria da justiça ao nível internacional. É isso que obriga os regimes pouco democráticos a organizar periodicamente eleições para se dar pelo menos a aparência de legitimidade. Porém, há exceções importantes, como o regime chinês. Portanto, a justificação normativa do valor dos regimes democráticos não pode resultar da constatação que uma maioria de países hoje em dia aceitam algumas diretrizes do modelo democrático, porque isso é somente uma constatação empírica e não uma justificação normativa.

Sobra então a questão normativa da legitimidade. Para avançar um pouco nessa questão normativa da legitimidade, gostaria de acrescentar duas distinções importantes: a distinção entre legitimidade e justiça, e a distinção entre legitimidade e justificação.

\section{Legitimidade e justiça}

A justiça social diz respeito às relações entre as pessoas dentro de um Estado. Admitindo que, desde a modernidade, as questões centrais da justiça dizem respeito à conciliação da igualdade e da liberdade, as respostas a essas questões variam. Mesmo no quadro de uma teoria da justiça como a de Rawls, as relações entre o primeiro princípio de iguais liberdades e o segundo princípio que diz respeito a uma certa igualdade social são relações discutidas e não há um consenso, por exemplo, sobre a interpretação do princípio de diferença.

Philip Pettit, que seguimos aqui, nota que a preocupação de justiça, isto é, essa atenção sobre as relações entre os cidadãos

deixa de considerar as relações entre os cidadãos como um todo e o Estado mesmo. Ignora a questão de se o Estado opera com legitimidade política ao impor um ordem social, quão justa essa ordem possa ser. É uma coisa afirmar que a ordem social imposta pelo Estado é justa e afirmar essa outra coisa que a imposição política dessa ordem é legítima. (PETTIT, 2012, p. 130). 
Em outras palavras: “A justiça social não implica a legitimidade política nem a legitimidade política implica a justiça social” (PETTIT, 2012, p. 130).

Essa afirmação pode chocar, porque estamos acostumados a pensar que, como Rawls o escreveu, “a justiça é a virtude primeira das instituições sociais assim como a verdade o é dos sistemas de pensamento” (RAWLS, 2008, § 1, 4). Por conseguinte, um regime justo é um regime legítimo. Porém, essa equivalência não deixa de colocar problemas. Podemos por exemplo pensar que um regime socialista que define os termos da igualdade social de maneira radical é o modelo mais justo. Mas sabemos também que essa imposição da igualdade — se for mesmo realizada - implica numa drástica limitação da liberdade e deve usar a força, senão a repressão, para impor-se. Nesse sentido, entendemos claramente porque esse tipo de governo falta de legitimidade, isto é, de reconhecimento pelos cidadãos. Da mesma maneira, um modelo libertário, como aquele de Nozick (1991) pode pretender a uma certa forma de justiça porque é o modelo que teoricamente respeita ao máximo a liberdade. No entanto, pode faltar totalmente de legitimidade porque não será aceito pela maioria dos cidadãos que não encontrarão nele o espaço necessário para exercer essa liberdade.

Essa não-coincidência entre justiça e legitimidade permite entender as críticas feitas ao contratualismo (BERTEN, 2010). Pois, o contrato social sendo uma ficção, um modelo idealizado de negociação, a questão da legitimidade enquanto tal nesse modelo é secundária. A atenção dos contratualistas se concentra sobre a justiça do procedimento, isto é sobre a justiça das condições segundo as quais as partes do contrato poderão discutir e elaborar os princípios que governarão as instituições sociais e políticas. O que será escolhido segundo esse procedimento, o resultado da deliberação, será considerado como legítimo. Essa forma de legitimidade pressupõe que o que é legítimo é o que decorre do contrato social - o que encontramos em Hobbes, Locke e Rousseau. A teoria contratualista não coloca a questão da adesão atual ou real, o fato que o reconhecimento da legitimidade de um poder atual não corresponde à ideia abstrata de um contrato primitivo. Aliás várias críticas do contratualismo avançaram o argumento da aceitação atual de um regime político: por que sentíramo-nos ligados por um contrato feito por nossos antepassados ou por um contrato imaginado por um filósofo? Nas formulações contratualistas e neo-contratualistas, a justiça é facilmente confundida com a legitimidade, isto é o ideal: 
de ter uma ordem social que é imposta somente na medida em que satisfaz os termos que esse povo realmente endossa. Nesse ideal as pessoas efetivamente ditam os termos sob os quais uma ordem social será aceita e, em toda interpretação dessa pretensão, elas podem ser ditas apoiar a ordem imposta. (PETTIT, 2012, p. 144).

A questão da justiça social é uma questão “relativa”, em um duplo sentido. Em primeiro lugar, qualquer que seja a concepção da justiça, a sua realização fica imperfeita e sempre ideal. Qualquer que seja o conceito de igualdade ou de liberdade, a sua realização fica problemática. E em segundo lugar, há várias concepções da justiça — entre outro problema, há a dificuldade de conciliar igualdade e liberdade. Não há dúvida que uma concepção republicana deve propor uma certa concepção da justiça, da igualdade, da liberdade. O conceito de igualdade, segundo o modelo liberal, dá prioridade às liberdades fundamentais iguais mas deve ser completado por uma teoria da justiça social. Porém, mesmo satisfatório do ponto de vista intelectual, isso não produz automaticamente a adesão. A questão da legitimidade é a questão da aceitação real da forma e do conteúdo das decisões do governo, uma aceitação que não é somente empírica, mas que é o resultado de um debate argumentado. Mas por ser uma aceitação real, ela deve suscitar os sentimentos correlativos. Kant pensava que o único sentimento que podia ser considerado moral era o "respeito” pela lei moral. Era uma maneira de conceder que sem um mínimo de apego ou de afetividade, não é possível o reconhecimento da justeza de uma proposição ou de uma decisão. Na verdade, esse pensamento kantiano tem uma significação profunda: qualquer sistema moral ou político é um sistema que engaja pessoas e é o fato dessas pessoas serem interessadas, ou participantes, que faz que nossa atitude a respeito de princípios de justiça é uma atitude possível de reconhecimento, isto é uma atitude que reconhece a legitimidade desses princípios.

\section{Legitimidade e justificação}

Para ter razões normativas de aceitar como legítimo um modelo político e/ou, as ações do governo, devemos poder produzir justificações ad hoc. A justificação, idealmente, deve ser acessível aos cidadãos e os mesmos deveriam ser interessados em conhecer as razões que levam o poder a tomar tal ou tal iniciativa. A despolitização e desmotivação da qual falamos na introdução podem ser o resultado seja da ausência de justificação acessível seja, por todos os motivos que evocamos, da ausência de interesse. Pode ser também que a justificação seja tão teórica e abstrata que ela fica fora do alcance do senso comum. Uma teoria da justiça, tão 
refinada e articulada, tão justificada que seja pode ficar um objeto de inúmeras discussões sem que os cidadãos comuns percebam sua pertinência ou sua significação. É nesse sentido que uma teoria da justiça pode não ser legítima apesar de justificada.

A justificação não pode ficar uma argumentação abstrata: a justificação toma sentido num contexto determinado, um contexto histórico e cultural. É por isso que certos tipos de justificações se tornam obsoletos. Por exemplo, nas sociedades democráticas contemporâneas, sociedades cada vez mais pluralistas, a justificação a partir da tradição se tornou mais frágil e, como Rawls o escreveu, invocar uma tradição particular, religiosa ou outra, arrisca de ser uma maneira repressiva de impor essa crença particular. No entanto, a legitimidade da tradição continua forte nos países muçulmanos e o cristianismo continua possuindo um capital justificador importante dentro dos países pluralistas. É verdade que, com a publicidade cada vez maior dos debates, com a internacionalização progressiva das informações sobre a variedade cultural, os argumentos tradicionais não podem mais ser considerados somente do ponto de vista empírico desde que são forçados a defenderem-se, isto é a argumentar. É nesse sentido que uma concepção meramente empírica da legitimidade encontra seus limites. Poderíamos aqui fazer uma diferença entre o tradicional e o "tradicionalista”. No contexto secularizado dos Estados democráticos contemporâneos, a pessoa que quer defender a legitimidade da tradição precisa argumentar. Por exemplo, os filósofos que, depois da Teoria da justiça de Rawls, foram chamados de “comunitaristas”, são pensadores que tentaram demonstrar que sem referência à tradição, à história particular de uma nação, os cidadãos não encontrarão motivos suficientes para aceitar a legitimidade do modelo democrático-liberal. Mas essas teses são teses argumentadas e a base empírica de suas demonstrações fica objeto de discussões. Isso significa que cada vez mais a legitimidade política é objeto de reflexão, de debates, de argumentações. Podemos esperar que esse processo de “conscientização” leve realmente a um processo de verdadeira democratização.

A diferença entre justiça e legitimidade poderia deixar supor que a justiça é um modelo teórico e ideal, um modelo normativo fundado sobre princípios, e que a legitimidade é uma realidade empírica, dependendo da aceitação real da política efetuada pelo governo, por exemplo, do fato que as decisões políticas podem ser avaliadas e confirmadas “democraticamente”, isto é não somente em relação a um contrato social originário mas num procedimento atual. Porém sobra uma dificuldade, já evocada quando criticamos as teses estritamente empíricas: o consenso, mesmo atual e real, é um fato contingente e empírico. 
Podem existir procedimentos perfeitamente democráticos onde maiorias tomam decisões que limitam drasticamente as liberdades - como é o caso em situações de terrorismo onde a segurança implica o estado de emergência ou de exceção. Acontece também que depois de um crime especialmente odioso um parlamente adota formas de direito penal que cancelam as seguranças jurídicas elementares. Isso mostra que a legitimidade não somente é diferente da justiça, mas que seu fundamento não pode ser reduzido a um processo democrático simples. Encontramos aqui o problema fundamental seguinte: não podemos prescindir de uma certa democracia representativa e do voto majoritário, mas esse simples mecanismo pode ter como resultado o fim da democracia. É por isso que a legitimidade não pode resultar simplesmente da vontade popular atual ou da vontade geral atual, mas precisa apoiar-se sobre argumentos justificativos numa discussão real e atualizada — quais que sejam os limites efetivos de qualquer deliberação.

Sem entrar agora numa discussão a respeito do modelo de democracia deliberativa, confrontar os conceitos de legitimidade e de justificação é necessário. Não pode-se dizer meramente que certas medidas políticas justificadas não são legítimas porque não conformes a constituição fundamental de uma nação ou os princípios básicos sobre os quais deveria ser construído o conjunto do aparelho jurídico. Pois isso significaria que existem princípios absolutos - princípios metafísicos anteriores a toda constituição, ou princípios constitucionais intangíveis que nem precisam mais de justificação.

Essa ideia de princípios primeiros intangíveis se encontra nas filosofias políticas de inspiração lockeana, mas perpassa várias concepções liberais em geral. Por exemplo, pode perguntar-se se o primeiro princípio da teoria da justiça de Rawls - a prioridade acordada às liberdades fundamentais - é um princípio absoluto ou é somente o princípio que a deliberação racional das partes do contrato originário estabelecera. Devemos interpretar a teoria da justiça como uma teoria política lockeana, fundamentada sobre a ideia que as pessoas têm certos direitos e deveres naturais, que incluem um amplo direito ao auto-governo ou à independência? Eu penso que, na verdade, a teoria de Rawls é tipicamente moderna e recusa toda fundamentação metafísica. A liberdade ou a autonomia não são dados naturais, não mais que a cidadania. São características de sujeitos modernos, racionais e razoáveis. Mas nessa leitura, a legitimidade é o resultado de uma deliberação contingente, porque histórica e culturalmente situada. Deveremos encontrar uma possibilidade de superação desse relativismo histórico. Deveríamos mostrar que uma pragmática histórica é a única maneira de defender 
argumentativamente as liberdades fundamentais. Mas, por enquanto, devemos enfrentar as várias correntes de filosofia política que de maneira ou outra pretendem apoiar-se sobre um fundamento metafísico ou antropológico. Por exemplo, o libertaríssimo e o utilitarismo, penso eu, são, nesse sentido, ainda filosofias políticas metafísicas.

Num modelo ideal e pós-metafísico de democracia deliberativa, poder-se-ia dizer que a legitimidade provém do fato que as decisões, depois de discutidas e aceitas majoritariamente, são tomadas respeitando os procedimentos estabelecidos dentro de um Estado de direito, com corpos representativos e uma separação dos poderes. Poder-se-ia analisar a representatividade real dos deputados e senadores — o que é um problema complexo —, a autonomia dos poderes, a justificação de uma corte suprema não eleita, etc. Na verdade, a realização institucional do ideal democrático é um trabalho contínuo de elaboração, revisão, correções, equilíbrio reflexivo. A dialética entre constituição, justificação e democracia é um processo que deve ser mantido. Por exemplo, no que diz mais precisamente à respeito da justificação, isto é, do conjunto de argumentos que apoiam uma opção mais que uma outra, devemos ainda determinar quem participa das discussões, quem é capaz de participar, como pode ter uma educação política suscetível de ajudar os cidadãos a participar às discussões. Voltamos aqui de novo à distinção entre justiça e legitimidade. A discussão mais racional pode alcançar um alto grau de justificação, ser conforme à concepção da justiça mais aceitável, sem que a argumentação seja acessível aos cidadãos normais.

Me parece que a desmotivação e a despolitização correspondem em parte a dificuldade de encontrar um equivalente positivo à ilegitimidade percebida. O caminho histórico para favorecer uma convergência entre justiça, legitimidade percebida e justificação reconhecida é longo e incerto. Enquanto não aparece essa convergência, as motivações políticas tendem geralmente a ser passionais, particularistas e excludentes. Mas existem experiências históricas onde o investimento emotivo se dirigiu explicitamente para com um "bem comum”. Não há dúvida, por exemplo, que logo depois da revolução russa, existia um entusiasmo de amplas camadas da sociedade e uma idealização passional do "comunismo". Provavelmente, não existiam nessa época as condições elementares para satisfazer esses desejos de justiça. Houve, e talvez há, vários casos de investimento sentimental em ideais de justiça. Uma análise dessas situações seria o objeto de estudos aprofundados. Mas pensamos que as condições mínimas para suscitar uma motivação e um apoio a um governo são primeiro uma diminuição das 
desigualdades, segundo, uma transparência das tomadas de decisão e, ultimamente, a maior liberdade de expressão possível.

\section{Referências}

ALENCAR, C. Síndrome de Antonieta. O Globo. Rio de Janeiro. 22 maio 2014. Disponível em: <http://oglobo.globo.com/opiniao/sindrome-de-antonieta-12560121>. Acesso em: 30 mar. 2017.

ARENDT, H. The human condition. Chicago: University of Chicago Press, 1958.

BERTEN, A. Porque Habermas não é e não pode ser contratualista, Ensaios Filosóficos, v. 1, abril, 2010, p. 6-18.

BOBBIO, N. Teoria das formas de governo. 10. ed. Brasília: UNB, 1980.

BUCHANAN, A. Justice, legitimacy, and self-determinação: moral foundations for international law. Oxford: Oxford University Press, 2004.

DANCY, J. Practical reality. Oxford: Oxford University Press, 2000.

HABERMAS, J. O discurso filosófico da modernidade. São Paulo: Martins Fontes, 2002.

HABERMAS, J. An awareness of what is missing. In: HABERMAS, Jürgen. An awareness of what is missing: faith and reason in a post-secular age. Cambridge: Polity Press, 2010. p. $15-23$.

HELD, D.; McGREW, A. The global transformations reader: an introduction to the globalization debate. 2. ed. Cambridge (UK): Polity Press, 2003.

HACKER, J. S.; PIERSON, P. P. Winner-take-all-politics: how Washington made the rich richer - and turned its back on the middle class. Berkeley: Simon \& Schuster, 2010.

HUME, D. Tratado da natureza humana: uma tentativa de introduzir o método experimental de raciocínio nos assuntos morais. 2. ed. São Paulo: Editora UNESP, 2000.

KORSGAARD, C. The sources of normativity. Cambridge: Cambridge University Press, 1996.

KORSGAARD, C. M. The sources of normativity: the tanner lectures on human values. 1992. Disponível em: <http://tannerlectures.utah.edu/_documents/a-to-z/k/korsgaard94.pdf>. Acesso em: 30 mar. 2017. 
METTLER, S. The submerged state: how invisible government policies undermine american democracy. Chicago: University of Chicago Press, 2011.

NOZICK, R. Anarchy, state and utopia. Oxford: Blackwell, 1974.

PETTIT, P. On the people's terms: a republican theory and model of democracy. Cambridge (UK): Cambridge University Press, 2012.

PIKETTY, T. Le capital au XXI $\mathbf{I}^{\mathbf{e}}$ siècle. Paris: Le Seuil, 2013.

RAWLS, J. A theory of justice. Oxford: Oxford University Press, 1971.

SCANLON, T. M. What we owe to each other. Cambridge: The Belknap Press of Harvard University Press, 1998.

SIERAKOWSKI, S.; TAYLOR, C. The de-politicization of politics. 2011. Disponível em: <http://www.eurozine.com/the-de-politicization-of-politics/>. Acesso em: 28 fev. 2017.

TAYLOR, C. Philosophy and the human sciences: philosophical papers II, Cambridge: Cambridge University Press, 1985.

WEBER, M. Economie et société. Paris: Plon, 1971.

WILLIAMS, B. Making sense of humanity and other philosophical papers. Cambridge: Cambridge University Press, 1995. 